\title{
Maternal swimming pool exposure during pregnancy in relation to birth outcomes and cord blood DNA methylation among private well users
}

\author{
Lucas A. Salas ${ }^{\mathrm{a}, \mathrm{b}}$, Emily R. Baker ${ }^{\mathrm{c}}$, Mark J. Nieuwenhuijsen ${ }^{\mathrm{d}, \mathrm{e}, \mathrm{f}}$, Carmen J. Marsit ${ }^{\mathrm{g}}$, \\ Brock C. Christensen ${ }^{\mathrm{a}, \mathrm{h}, \mathrm{i}}$, Margaret R. Karagas ${ }^{\mathrm{a}, \mathrm{b}, *}$ \\ ${ }^{a}$ Department of Epidemiology, The Geisel School of Medicine at Dartmouth, Dartmouth College, Lebanon 03756, NH, USA \\ ${ }^{\mathrm{b}}$ The Children's Environmental Health and Disease Prevention Research Center at Dartmouth, Lebanon 03756, NH, USA \\ ${ }^{\mathrm{c}}$ Department of Obstetrics and Gynecology, The Geisel School of Medicine at Dartmouth, Dartmouth College, Lebanon 03756, NH, USA \\ ${ }^{\mathrm{d}}$ ISGlobal, The Barcelona Institute for Global Health, Barcelona 08003, Catalonia, Spain \\ e Universitat Pompeu Fabra (UPF), Barcelona 08003, Catalonia, Spain \\ ${ }^{\mathrm{f}}$ CIBER Epidemiología y Salud Pública (CIBERESP), Barcelona 08003, Catalonia, Spain \\ ${ }^{\mathrm{g}}$ Department of Environmental Health, Rollins School of Public Health of Emory University, Atlanta 30322, GA, USA \\ ${ }^{\mathrm{h}}$ Department of Molecular and Systems Biology, Geisel School of Medicine at Dartmouth, Lebanon 03756, NH, USA \\ ${ }^{\mathrm{i}}$ Department of Community and Family Medicine, Geisel School of Medicine at Dartmouth, Lebanon 03756, NH, USA
}

A R T I C L E IN F O

Handling Editor: Martí Nadal

\begin{abstract}
A B S T R A C T
Swimming in pools during pregnancy may expose the fetus to water disinfection by-products (DBP). As yet, our understanding of the impacts on DBPs on the fetus is uncertain. Individuals with public water systems are typically exposed to DBPs through drinking, showering and bathing, whereas among those on private water systems, swimming in pools may be the primary exposure source. We analyzed the effects of maternal swimming on birth outcomes and cord blood epigenetic changes in the New Hampshire Birth Cohort Study, a cohort of pregnant women with households on private water systems. Information about swimming in pools during pregnancy was obtained from 1033 women via questionnaires. Swimming pool use and duration were modeled using linear regression with newborn weight, length, and head circumference (z-scores) and genome wide cord blood DNA methylation as the outcomes and with adjustment for potential confounders. Overall $19.7 \%$ of women reported swimming in a pool during pregnancy. Among swimmers, duration of swimming was inversely related to head circumference $(-0.02 \mathrm{z}$-score per $10 \%$ increase in duration, $\mathrm{P}=0.004)$. No associations were observed with birth weight, length or DNA methylation modifications. Our findings suggest swimming pool exposure may impact the developing fetus although longer-term studies are needed.
\end{abstract}

\section{Introduction}

The American College of Obstetricians and Gynecologists includes swimming as a safe exercise during pregnancy ("Committee Opinion No. 650", 2015). Swimming, as a physical activity, has benefits for cardiovascular health, fitness, and respiratory function. Swimming pools also contain microbes and potential toxicants such as disinfection by-products (DBP) (De Filippis et al., 2017; Dufour et al., 2017; Ekowati et al., 2017; Manasfi et al., 2017). DBPs are a complex mixture of organic chemicals formed from reactions of the brominated or chlorinated compounds used in pool disinfection with organic matter such as microbes (Manasfi et al., 2017; Richardson et al., 2010).
DBP exposure through drinking water has been consistently associated with risk of bladder cancer across different study populations (Costet et al., 2011), and possibly with other malignancies (e.g. colorectal, kidney and breast cancer), alterations in the sperm quality, and disruption of the menstrual cycle (Villanueva et al., 2015). In mechanistic studies, swimming pool exposure has been associated with changes in gene expression, changes in micronuclei, DNA damage, and epigenetic alterations (Espín-Pérez et al., 2018; Kogevinas et al., 2010; Salas et al., 2017, 2015; Villanueva et al., 2015; Wang and Wang, 2013). Composition of DBPs, and in turn their toxicity, differs in drinking water and pools. In pools, the organic load fluctuates with factors such as number of swimmers, water source, and surrounding

\footnotetext{
* Corresponding author at: Department of Epidemiology, The Geisel School of Medicine at Dartmouth, Dartmouth College, Lebanon 03756, NH, USA.

E-mail addresses: Lucas.A.Salas.Diaz@Dartmouth.Edu (L.A. Salas), emily.r.baker@dartmouth.edu (E.R. Baker), mark.nieuwenhuijsen@isglobal.org (M.J. Nieuwenhuijsen), carmen.j.marsit@emory.edu (C.J. Marsit), brock.c.christensen@dartmouth.edu (B.C. Christensen), margaret.r.karagas@dartmouth.edu (M.R. Karagas).
} 
environment (e.g. indoor versus outdoor pools) (Chowdhury et al., 2014; Lourencetti et al., 2012; Manasfi et al., 2017; Richardson et al., 2010). Pool disinfection systems vary (Villanueva et al., 2007) and regulations for disinfection in private versus public pools follow local laws which vary by region (World Health Organization, 2006). Personal care products, sweat, urine, and feces are usually not present, or present in trace concentrations in drinking water (Y. Yang et al., 2017). In contrast, these compounds are often present in swimming pools where they can react with disinfectants to create potentially toxic compounds (World Health Organization, 2006). Halobenzoquinones, for example, can be 100 times more concentrated in swimming pool water compared to drinking water, due to reactions with consumer products. The health impacts of these compounds are as yet unknown (Wang et al., 2013).

Epidemiologic studies have reported potential reproductive toxicity associated with DBPs including congenital anomalies and decreased birth weight, but not consistently so (Agopian et al., 2013a; Grellier et al., 2010; Juhl et al., 2010; Nieuwenhuijsen et al., 2013, 2009, 2002; Patelarou et al., 2011; Stayner et al., 2014; Villanueva et al., 2011; Wright et al., 2011). Among the design challenges for these studies are that DBP exposure largely occurs from tap water used for drinking, cooking and bathing. Thus, among those with public water the fraction of exposure from swimming pools may be relatively small as compared to those using non-disinfected water sources such as private, unregulated wells for whom swimming pools may be the primary source of exposure. For this reason, we used data from a pregnancy cohort of private well users to investigate the relation between maternal swimming in pools and newborn anthropometric characteristics. We further explored whether exposure to swimming in pools affected umbilical cord blood DNA methylation.

\section{Methods}

\subsection{Study population}

The general design of the New Hampshire Birth Cohort study (NHBCS) has been described previously (Gilbert-Diamond et al., 2011). Briefly, eligibility criteria included English speaking, mentally competent with a singleton pregnancy, 18-45years of age, whose primary source of residential water was a private well. Women who planned to move during pregnancy were excluded. All study participants provided written informed consent prior to participation according to the guidelines of the Committee for the Protection of Human Subjects at Dartmouth.

\subsection{Maternal and newborn characteristics}

Questionnaires were administered both during pregnancy and about two weeks after delivery. Prenatal and delivery medical records were reviewed for maternal-newborn anthropometric factors i.e., maternal and birth weight, maternal height, birth length, and birth head circumference. Gestational age was defined by clinical record or first trimester ultrasound information. Newborn anthropometry and maternal weight gain were converted to z-scores (standard deviation (SD) over the mean) according to Fenton's and Hutcheon's methods (Fenton and Kim, 2013; Hutcheon et al., 2013). Maternal weight gain was then categorized as adequate ( -2 to $2 \mathrm{z}$-scores), inadequate ( $<-2 \mathrm{z}$-scores) and excessive weight gain ( $>2$ z-scores). Maternal smoking was defined as any smoking during or before pregnancy. For those subjects with cord blood DNA methylation, a beta-value below 0.80 in the AHRR cg05575921 probe was considered as smoking during pregnancy irrespective of the questionnaire response (Philibert et al., 2014; Reese et al., 2017). Birth weight for gestational age was classified according to Fenton method as adequate, small or large for gestational age (Fenton and Kim, 2013). Pre-pregnancy maternal body mass index was classified as $<18.5$ underweight, 18.5 to $<25$ adequate, 25 to $<30$ overweight, $\geq 30$ obesity. Maternal education attainment level was classified as high school or less or college or higher. Exercise questions included whether women exercised during the 1st, 2nd, or 3rd trimester of pregnancy, and if yes, the frequency and average time spent exercising as well as the intensity of workout (light, moderate, high intensity). Maternal exercise intensity during pregnancy was classified as self-reported low or no exercise, or moderate to high intensity exercise. The amount of physical activity/exercise was further classified according to current recommendations: less than minimum activity recommended ( $<60 \mathrm{~min} /$ gestational week), minimum activity recommended $(60-<180 \mathrm{~min} /$ gestational week), optimal activity recommended ( $\geq 180 \mathrm{~min} /$ gestational week).

\subsection{Swimming in pools during pregnancy}

Pre- and post-natal questionnaires asked about swimming in pools by trimester of the pregnancy. Specifically, women were asked: 1) "Did you swim regularly in an indoor or outdoor pool during the (first, second, third) trimester of pregnancy?" 2) "How much time did you spend in an indoor or outdoor pool during the (first, second, third) trimester of pregnancy (hours and minutes)?" 3) "How many times per week/month did you swim in an indoor or outdoor pool during the (first, second, third) trimester of pregnancy?". We classified women based on whether they ever swam in a pool at any time during pregnancy (yes/no), and cumulative swimming exposure was estimated as from the average minutes of swimming in a pool per trimester reported and totaling the number of minutes across the three trimesters and dividing per total weeks of gestation. Because swimming intensity was highly right skewed, we used a signedlog ${ }_{10}$ transformation $\left(\log _{10}\right.$ transformation with zeroes preserved) in analyses that included never swimmers, and a $\log _{10}$ transformation in analyses restricted to ever swimmers. We further categorized participants into: never swimmers (no exposure during the pregnancy), occasional swimmers $(<15 \mathrm{~min} /$ week of gestation), and regular swimmers ( $15 \mathrm{~min}$ or more/week of gestation).

\subsection{DNA extraction and genome-wide DNA methylation array}

Cord blood samples were collected at the time of delivery by trained obstetrical staff. Within $24 \mathrm{~h}$ of collection, samples were processed then stored at $-80^{\circ} \mathrm{C}$. DNA was isolated from the buffy coat fraction using DNeasy $^{\circledR}$ blood and tissue kits (Qiagen, Valencia, CA) and bisulfite converted using the EZ DNA Methylation kit (Zymo, Irvine, CA). Samples were randomized across several plates and subsequently subjected to epigenome-wide DNA methylation assessment. Two generations of array were used for evaluating DNA methylation: 105 samples were run on the Illumina Infinium HumanMethylation450 BeadChip, which measured $\sim 485,000 \mathrm{CPG}$ sites genome-wide (Illumina, San Diego, CA). Later, 237 additional samples were run on the Infinium HumanMethylationEPIC Beadchip (EPIC) measuring $\sim 860,000 \mathrm{CpG}$ sites genome-wide (Illumina, San Diego, CA). Microarrays were processed at the Biomedical Genomics Center at the University of Minnesota (Minneapolis, MN) following standard protocols. The methylation status for each individual $\mathrm{CpG}$ locus was calculated as the ratio of fluorescent signals $(\beta=\operatorname{Max}(M, 0) /[\operatorname{Max}(M, 0)+\operatorname{Max}$ $(\mathrm{U}, 0)+100]$ ), ranging from 0 (no methylation) to 1 (complete methylation) using the average probe intensity for the methylated (M) and unmethylated (U) alleles. The data were assembled using GenomeStudio methylation software (Illumina, San Diego, CA) without normalization per the manufacturer's instructions. We read the idat files using the minfi and EnMix R package for preprocessing and normalization (Aryee et al., 2014; Fortin et al., 2017; Xu et al., 2016). Our pipeline included array control probes to assess sample quality and evaluate potential problems such as poor bisulfite conversion or colorspecific issues for each array as described (Cardenas et al., 2015; Koestler et al., 2013). The current analyses were restricted to probes that were shared across both platforms (453,093 common CpG sites). 


\subsection{Statistical analyses}

Our analyses excluded individuals with extreme newborn anthropometry z-scores ( $>4$ or $<-4 \mathrm{SD}$ ), children born prematurely, women who experienced gestational diabetes and newborns who were reported as non-white to reduce genetic heterogeneity (only ten subjects in all the birth cohort). Newborn weight, length and head circumference z-scores were modeled using linear regression. Models were adjusted for the following potentially confounding factors: gestational age, newborn sex, maternal age at delivery, maternal smoking, prepregnancy maternal body mass index, maternal education level, maternal exercise intensity during pregnancy and amount of physical activity/exercise. For the birth length and head circumference models, they were also adjusted for birth weight for gestational age. All the covariates with missing data were imputed using multiple imputation chain estimation (mice) using as parameters a seed number of 123, 20 iterations and 50 imputations (Van-Buuren and Groothuis-Oudshoorn, 2011). The results of the mice estimates were visually explored using stripplots to ensure that the imputation results were consistent with the sample distribution. We also investigated effect modification by newborn sex in stratified models and by adding interaction terms to our models. Lastly, we fit a generalized additive model to examine the shape of relation between swimming intensity among swimmers and birth outcomes. As sensitivity analyses, we also performed this analysis in the full dataset including non-swimmers.

\subsection{DNA methylation analysis}

DNA methylation values were analyzed as $\beta$-values. $\beta$-Values were background corrected using methylumi-noob (Fortin et al., 2017, 2014). Principal components analysis and multiple dimension scaling were used to identify potential effects related to the different platforms and other technical batches. Probes with detection P-values > $10 \mathrm{E}-07$ compared to the background probes were flagged as bad quality probes and excluded. Samples with low bisulfite conversion (less than 3SD of the mean), or $>5 \%$ of the CpGs flagged as bad quality probes were flagged as bad quality samples and excluded from the analyses. In addition, samples which $\beta$-value distribution was over the outer fences ( \pm 3 times the interquartile range) of the general distribution were also excluded as outliers. Copy number of the $\mathrm{X}$ and $\mathrm{Y}$ chromosome were used to predict the sex of the sample (Aryee et al., 2014). If the sample predicted sex was not concordant, the sample was excluded from the analyses. All CpG loci on X and Y chromosomes and loci with potential problems of cross-reactivity, tracking to polymorphisms with minor allele frequencies over $5 \%$ for the general population, or common copy number alterations, (Zhou et al., 2017) were excluded from the analysis, leaving 381,831 autosomal CpG loci in 327 samples.

\subsection{Cell mixture deconvolution analysis}

Using the raw beta-values we inferred the cell proportions using the quadratic programming/constrained projection method of Houseman (Houseman et al., 2012). As we were using DNA from cord blood samples, we used a combination of three current available references for cord blood and two adult references (Bakulski et al., 2016; de Goede et al., 2016; Gervin et al., 2016; Reinius et al., 2012; Salas et al., 2018a, $2018 \mathrm{~b})$ for inferring the distribution of six leukocytes subpopulations (granulocytes, B cells, CD4(+) T cells, CD8(+) T cells, Natural Killer lymphocytes, and monocytes), and the nucleated red blood cells proportions. We used the estimateCellCounts 2 method implemented in FlowSorted.Blood.EPIC (Salas et al., 2018a, 2018b) using 550 CpGs selected using IDOL (Koestler et al., 2016) (manuscript in preparation). The cell estimates allowed us to quantify the proportion of total variability in cord blood DNA methylation explained by estimated immune cell composition.

\subsection{Locus-by-locus analysis for detecting differentially methylated $C p G$ loci}

We implemented a locus-by-locus analysis aimed at identifying differentially methylated $\mathrm{CpG}$ sites based on swimming intensity using the package limma (Ritchie et al., 2015). Briefly, two different linear models were fit to each CpG site separately, and modeled $\beta$-values of the DNA methylation as the response versus a categorical swimming pool exposure (never, occasional swimmer, regular swimmer) or versus the log transformed total minutes of swimming in a pool during pregnancy per week of gestation. All the models were adjusted for maternal age at delivery, newborn sex, birth weight for gestational age, maternal smoking, pre-pregnancy maternal body mass index, maternal weight gain categories, exercise intensity during pregnancy, amount of physical activity during pregnancy, estimated cell proportions (excluding granulocytes to avoid collinearity). Three different methods were explored to control for potential batch effects related to the use of two different array platforms: global normalization by platform using ComBat, inclusion of surrogate variables derived from the negative control probes in the models, or adding the Slide as a fixed-effect covariate to the models (Johnson et al., 2007; Leek et al., 2012). Although our examination was exploratory in nature, P-values were adjusted for multiple comparisons by computing the Benjamini-Hochberg Q-values (Benjamini and Hochberg, 1995). All analyses were carried out using the R statistical package, version 3.5.0 (R Core Team, 2017) (Vienna, Austria; www.r-project.org/).

\section{Results}

From the 1523 subjects in the cohort 1033 had information about swimming in pools. From those 1033 subjects, 327 had also cord blood DNA methylation information. The characteristics of infants and mothers were similar between cohort members analyzed for birth outcomes and the subset analyzed for cord blood DNA methylation (Table 1). Among the selected 1033 pregnant women, 830 (80.3\%) reported never attending to swimming pools during pregnancy, 86 (9.8\%) reported swimming $15 \mathrm{~min}$ or less per week, and $102(11.6 \%)$ swam regularly ( $>15 \mathrm{~min}$ per week) (Table 1 ). For those who swam, the median duration of swimming throughout pregnancy was $16 \mathrm{~min}$ per week (Table 1). Total minutes of swimming per week during pregnancy was only weakly correlated to total minutes of exercise per week (Spearman's correlation coefficient $=0.1$ ). Physical activity also was unrelated to birth weight, length or head circumferences z-scores.

We modeled the association between swimming pool exposure and z-scores of three newborn anthropometric characteristics (birth weight, length and head circumference). After adjusting for potential confounders, no statistically significant associations were observed in the full dataset for birth weight and length, (Table 2). Larger head circumference was observed among occasional swimmers (mean $0.22 \mathrm{z}$ larger) compared to never swimmers $(\mathrm{P}=0.03)$; but this was not observed among regular swimmers. Among swimmers, we observed a decrease in head circumference with increased cumulative swimming pool exposure (minutes in the pool/week of gestation) as a continuous variable. A head circumference $\mathrm{z}$ score reduction of 0.02 per $10 \%$ increase in the cumulative swim exposure was observed in the linear and in the generalized additive models (Table 2, Fig. 1). No evidence of effect modification was observed when stratifying by newborn sex.

\subsection{DNA methylation and DNA methylation derived analyses}

We explored if the exposure to swimming in pools altered the cord blood DNA methylation using an Epigenome wide DNA methylation Association analysis. None of the interrogated CpGs reached the Qvalue cut-off and all of the top ones were over a $\mathrm{Q}$-value $>0.1$. The models yielded similar results using the various batch effect correction strategies. When exploring the cord blood cell composition estimates derived from the DNA methylation information, for those who regularly 
Table 1

Selected characteristics of NHBCS participants.

\begin{tabular}{|c|c|c|}
\hline & $\begin{array}{l}\text { NHBCS subjects with swimming } \\
\text { pool exposure information }\end{array}$ & $\begin{array}{l}\text { DNA methylation } \\
\text { subset }\end{array}$ \\
\hline & $\mathrm{n}=1033$ & $\mathrm{n}=327$ \\
\hline \multicolumn{3}{|l|}{ Newborn characteristics } \\
\hline \multicolumn{3}{|l|}{ Sex } \\
\hline Female n (\%) & $509(49.3)$ & $142(43.4)$ \\
\hline Male n (\%) & $524(50.7)$ & $185(56.6)$ \\
\hline Gestational age-weeks (mean $\pm \mathrm{SD}$ ) & $39.8 \pm 1.1$ & $39.8 \pm 1.0$ \\
\hline Birth weight-grams (mean \pm SD) & $3504 \pm 462$ & $3525 \pm 434$ \\
\hline Birth weight-z (mean \pm SD) & $0.08 \pm 0.87$ & $0.10 \pm 0.82$ \\
\hline \multicolumn{3}{|l|}{ Birth weight to gestational age } \\
\hline Adequate for gestational age $\mathrm{n}(\%)$ & $899(87.0)$ & $290(88.7)$ \\
\hline Small for gestational age $\mathrm{n}(\%)$ & $51(4.9)$ & $10(3.1)$ \\
\hline Large for gestational age $\mathrm{n}(\%)$ & $83(8.0)$ & $27(8.3)$ \\
\hline Birth length-cm (mean \pm SD) & $51 \pm 2.5$ & $51.2 \pm 2.6$ \\
\hline Birth length-z (mean \pm SD) & $0.17 \pm 1.03$ & $0.24 \pm 1.06$ \\
\hline Head circumference-cm (mean \pm SD) & $34.8 \pm 1.5$ & $34.9 \pm 1.4$ \\
\hline Head circumference-z (mean \pm SD) & $0.01 \pm 1.02$ & $0.08 \pm 1.01$ \\
\hline \multicolumn{3}{|l|}{ Head circumference categories (sex and gestational age adjusted) } \\
\hline Normocephalia ( -2 to $2 \mathrm{z}$-scores) $\mathrm{n}(\%)$ & 975 (94.4) & $312(95.4)$ \\
\hline Microcephalia (< $<-2$ z-scores) n (\%) & $28(2.7)$ & $6(1.8)$ \\
\hline Macrocephalia (> 2 z-scores) n (\%) & $30(2.9)$ & $9(2.8)$ \\
\hline \multicolumn{3}{|l|}{ Fetal growth restriction } \\
\hline No fetal growth restriction $\mathrm{n}(\%)$ & $982(95.1)$ & 317 (96.9) \\
\hline Asymmetric fetal growth restriction $\mathrm{n}(\%)$ & $42(4.1)$ & $9(2.8)$ \\
\hline Symmetric fetal growth restriction $\mathrm{n}(\%)$ & $9(0.9)$ & $1(0.3)$ \\
\hline \multicolumn{3}{|l|}{ Race (self-determined) } \\
\hline White $\mathrm{n}(\%)$ & $1033(100.0)$ & $327(100.0)$ \\
\hline \multicolumn{3}{|l|}{ Maternal characteristics } \\
\hline Maternal age-years (mean \pm SD) & $31.3 \pm 4.8$ & $31.1 \pm 4.9$ \\
\hline Maternal weight gain z-score (mean $\pm S D$ ) & $0.02 \pm 0.88$ & $0.13 \pm 0.86$ \\
\hline \multicolumn{3}{|l|}{ Maternal weight gain categories (according to z-scores) } \\
\hline Adequate weight gain ( -2 to $2 \mathrm{z}$-scores) $\mathrm{n}(\%)$ & $974(94.3)$ & $310(94.8)$ \\
\hline Inadequate weight gain $(<-2$ z-scores) $\mathrm{n}(\%)$ & $14(1.4)$ & $5(1.5)$ \\
\hline Excessive weight gain (> 2 z-scores) n (\%) & $17(1.6)$ & $6(1.8)$ \\
\hline Missing $n(\%)$ & $28(2.7)$ & $6(1.8)$ \\
\hline \multicolumn{3}{|l|}{ Pre-pregnancy body mass index classification } \\
\hline Normal weight $\left(18.5-24.9 \mathrm{~kg} / \mathrm{m}^{2}\right) \mathrm{n}(\%)$ & $546(52.9)$ & $175(53.5)$ \\
\hline Underweight $\left(<18.5 \mathrm{~kg} / \mathrm{m}^{2}\right) \mathrm{n}(\%)$ & $19(1.8)$ & $4(1.2)$ \\
\hline Overweight $\left(25-29.9 \mathrm{~kg} / \mathrm{m}^{2}\right) \mathrm{n}(\%)$ & $278(26.9)$ & $84(25.7)$ \\
\hline Obese $\left(\geq 30 \mathrm{~kg} / \mathrm{m}^{2}\right) \mathrm{n}(\%)$ & 185 (17.9) & $62(19.0)$ \\
\hline Missing n (\%) & $5(0.5)$ & $2(0.6)$ \\
\hline \multicolumn{3}{|l|}{ Maternal smoking } \\
\hline No $\mathrm{n}(\%)$ & $894(86.5)$ & $276(84.4)$ \\
\hline Yes n (\%) & $139(13.5)$ & $51(15.6)$ \\
\hline \multicolumn{3}{|l|}{ Maternal education level } \\
\hline High school graduate or lower $\mathrm{n}(\%)$ & $121(11.7)$ & $39(11.9)$ \\
\hline Some college or higher n (\%) & $899(87.0)$ & $284(86.9)$ \\
\hline Missing n (\%) & $13(1.3)$ & $4(1.2)$ \\
\hline \multicolumn{3}{|l|}{ Maternal exercise during pregnancy } \\
\hline Cumulative exercise min per week of pregnancy (median [IQR]) & $63[0,113]$ & $55[0,90]$ \\
\hline \multicolumn{3}{|l|}{ Exercise during pregnancy } \\
\hline Less than recommended $(<60 \mathrm{~min} /$ week $) \mathrm{n}(\%)$ & $415(40.2)$ & $157(48.0)$ \\
\hline Minimum recommended $(60-<180 \mathrm{~min} /$ week $) \mathrm{n}(\%)$ & $385(37.3)$ & $108(33.0)$ \\
\hline Optimal recommended ( $\geq 180 \mathrm{~min} /$ week) n (\%) & $99(9.6)$ & $33(10.1)$ \\
\hline Missing n (\%) & $134(13.0)$ & $29(8.9)$ \\
\hline \multicolumn{3}{|l|}{ Exercise intensity } \\
\hline No exercise or low intensity only n (\%) & $497(48.1)$ & $175(53.5)$ \\
\hline Moderate or high intensity n (\%) & $402(38.9)$ & $123(37.6)$ \\
\hline Missing n (\%) & $134(13.0)$ & $29(8.9)$ \\
\hline \multicolumn{3}{|l|}{ Swimming pool exposure during pregnancy } \\
\hline $\begin{array}{l}\text { Total swimming pool min per week of pregnancy in those who } \\
\text { swam during pregnancy }{ }^{\mathrm{a}} \text { (median [IQR]) }\end{array}$ & $16[6,28]$ & $20[10,37]$ \\
\hline Swimming pool exposure categories & & \\
\hline Never n (\%) & $830(80.3)$ & $264(80.7)$ \\
\hline Occasional swimmer (< $15 \mathrm{~min} /$ week) $\mathrm{n}(\%)$ & $97(9.4)$ & $25(7.6)$ \\
\hline Regular swimmer ( $\geq 15$ min/week) n (\%) & $106(10.3)$ & $38(11.6)$ \\
\hline
\end{tabular}

${ }^{\mathrm{a}} \mathrm{n}$ of this row corresponds to the sum of ever swimmers (occasional plus regular swimmers).

swam, the mean proportion of $\mathrm{CD} 4(+) \mathrm{T}$ lymphocyte was lower $(\mathrm{P}=0.002)$ and the mean proportion of erythroblasts and nucleated red blood cells was higher $(P=0.04)$ compared to the never or occasional swimmers after adjusting for gestational age, sex of the newborn, weight adequacy, maternal smoking, maternal BMI, maternal weight gain, maternal exercise, maternal socioeconomic status 
Table 2

Association between swimming pool exposure during pregnancy and newborn anthropometric characteristics.

\begin{tabular}{|c|c|c|c|c|c|c|}
\hline & \multicolumn{2}{|l|}{ Weight-z } & \multicolumn{2}{|l|}{ Length-z } & \multicolumn{2}{|l|}{ Head circumference-z } \\
\hline & $\beta[95 \% \mathrm{CI}]$ & $\mathrm{P}$ & $\beta[95 \% \mathrm{CI}]$ & $\mathrm{P}$ & $\beta[95 \% \mathrm{CI}]$ & $\mathrm{P}$ \\
\hline Swimming pool exposure & $\mathrm{N}=1033$ & & $\mathrm{~N}=1033$ & & $\mathrm{~N}=1033$ & \\
\hline Never & Reference & & Reference & & Reference & \\
\hline Occasional swimmer & $0.06[-0.12,0.24]$ & 0.5 & $0.004[-0.20,0.20]$ & 0.9 & $0.22[0.03,0.41]$ & 0.03 \\
\hline Regular swimmer & $0.06[-0.12,0.24]$ & 0.5 & $0.06[-0.13,0.24]$ & 0.6 & $-0.06[-0.25,0.12]$ & 0.5 \\
\hline Cumulative swimming pool exposure (per $10 \%$ increase in $\min /$ week) ${ }^{\mathrm{a}, \mathrm{b}}$ & $0.002[-0.001,0.007]$ & 0.2 & $0.002[-0.003,0.006]$ & 0.5 & $-0.0003[-0.005,0.004]$ & 0.9 \\
\hline Swimming pool exposure ever & $\mathrm{N}=203$ & & $\mathrm{~N}=203$ & & $\mathrm{~N}=203$ & \\
\hline $\begin{array}{l}\text { Per } 10 \% \text { increase in cumulative swimming pool exposure (min)/week of } \\
\text { gestation }^{\text {a,c }}\end{array}$ & $0.005[-0.005,0.02]$ & 0.3 & $0.003[-0.007,0.01]$ & 0.6 & $-0.02[-0.03,-0.005]$ & 0.004 \\
\hline
\end{tabular}

${ }^{a}$ Models were adjusted for gestational age, newborn sex, maternal age, maternal smoking, maternal body mass index classification, maternal weight gain category, exercise amount during pregnancy, maternal exercise intensity during pregnancy, and maternal education level. The length-z and the head circumference-z models were also adjusted for weight adequacy for gestational age.

b A Signed $\log _{10}$ transformation was used preserving the zeroes from the transformation, the beta coefficient was transformed back into a percentage increase for interpretation.

c Among women who reported ever swimming. The $\log _{10}$ transformation was used, the beta coefficient was transformed back into a percentage increase for interpretation.

(Table 3). Based on our model, regular swimmers on average had 3.3\% less CD4T [95\% CI: $-5.2,-1.3 \%$ ], and 3.3\% higher erythroblast levels [95\% CI: $0.7,5.9 \%]$ than never swimmers. No differences were observed for occasional swimmers.

\section{Discussion}

In our study of pregnant women who used private water systems, we found no differences in birth weight or length compared to never swimmers. Head circumference was inversely related to the amount of time swimming in a pool during pregnancy among those who swam. In the subset of infants with data on cord blood DNA methylation we estimated cord blood cell composition and observed a statistically significant reduction in the CD4(+) T lymphocytes and increase in erythroblast (and/or any circulating nucleated red blood cell) proportions among infants whose mothers regularly swam compared to those who never or occasionally swam.

Prior studies have examined the potential reproductive toxicity of DBPs but the findings have been inconclusive (Agopian et al., 2013a, 2013b; Grellier et al., 2010; Juhl et al., 2010; Nieuwenhuijsen et al., 2013, 2009, 2002; Patelarou et al., 2011; Stayner et al., 2014;
Villanueva et al., 2011; Wright et al., 2011). With respect to drinking water DBP exposure, a recent meta-analysis of six different studies reported a small, statistically significant increase of the risk of being small for gestational age in relation to trihalomethane exposure in drinking water (OR: 1.01 [95\% CI: 1.001-1.019] per $10 \mu \mathrm{g}$ of trihalomethanes/ L) (Grellier et al., 2010). An earlier study reported a slight increase in birth weight for the ever swimmers $(<1 \mathrm{~h}$ per week, and $>2 \mathrm{~h}$ per week) compared to the never swimmers (although not statistically significant) in two large U.K. cohorts (Nieuwenhuijsen et al., 2002). A Danish cohort did not detect an association with birth weight, but found a decrease in both preterm birth and congenital anomalies among women who swam early in pregnancy compared to those who did not exercise during their pregnancies (Juhl et al., 2010). In this latter study, a weak negative association between swimming and head circumference was observed $(\beta:-0.03 \mathrm{~cm} \quad[95 \%$ CI: $-0.06 \mathrm{~cm}$, $0.007 \mathrm{~cm}]$ ) compared to those who did not exercise. Unlike the previous studies, our study, evaluated trends by cumulative exposure to swimming pools among those who swam. This approach, in addition to adjustment for amount of physical exercise and other covariates, reduced the potential for confounding.

In the subset of infants with available data on umbilical cord blood

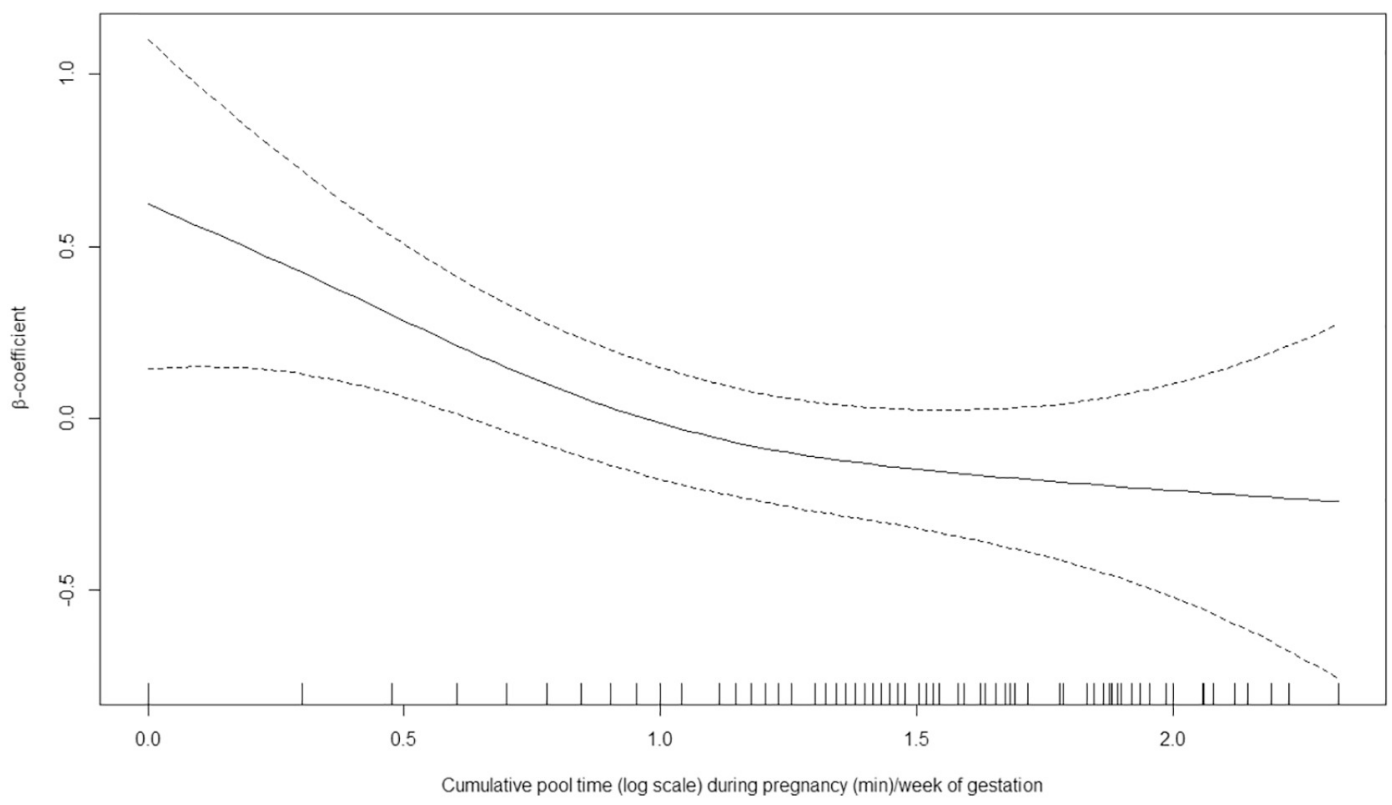

Fig. 1. Generalized Additive Model head circumference (z) vs. cumulative pool time in minutes/week of gestation ever swimmers $1.91 \mathrm{df}$, P-value $=0.01 \mathrm{n}=203$. 
Table 3

Cord blood cell proportion estimates derived from the DNA methylation by swimming pool exposure.

\begin{tabular}{|c|c|c|c|c|c|}
\hline \multirow[t]{2}{*}{ Cord blood cell proportion estimates } & \multirow{2}{*}{$\begin{array}{l}\text { Never swimmer } \\
\mathrm{n}=264\end{array}$} & Occasional swimmer & \multirow{2}{*}{$\begin{array}{l}\text { Regular swimmer } \\
\mathrm{n}=38\end{array}$} & \multicolumn{2}{|l|}{ All the subjects } \\
\hline & & $\mathrm{n}=25$ & & $\mathrm{n}=327$ & $\mathrm{P}$ \\
\hline Granulocytes & $55.79 \pm 9.19$ & $55.22 \pm 9.37$ & $56.48 \pm 8.88$ & $55.82 \pm 9.15$ & 0.9 \\
\hline B cells & $6.40 \pm 2.64$ & $6.41 \pm 2.81$ & $5.93 \pm 2.21$ & $6.35 \pm 2.61$ & 0.6 \\
\hline CD4(+) T lymphocytes & $14.71 \pm 5.92$ & $16.11 \pm 4.48$ & $11.53 \pm 4.52$ & $14.45 \pm 5.77$ & 0.002 \\
\hline CD8(+) T lymphocytes & $3.71 \pm 2.45$ & $4.02 \pm 2.35$ & $3.58 \pm 2.63$ & $3.72 \pm 2.46$ & 0.8 \\
\hline NK & $5.37 \pm 2.92$ & $4.52 \pm 2.89$ & $5.62 \pm 2.25$ & $5.33 \pm 2.85$ & 0.3 \\
\hline Monocytes & $8.67 \pm 3.08$ & $8.45 \pm 2.95$ & $8.32 \pm 3.09$ & $8.62 \pm 3.06$ & 0.8 \\
\hline Erythroblasts & $7.48 \pm 7.04$ & $7.08 \pm 8.20$ & $10.59 \pm 7.71$ & $7.81 \pm 7.26$ & 0.04 \\
\hline
\end{tabular}

DNA methylation, we found no clear associations between maternal swimming and DNA methylation alterations. To our knowledge only one previous study examined DNA methylation changes associated with DBP exposure during pregnancy (P. Yang et al., 2017). Yang et al. evaluated several maternal biomarkers (blood trihalomethanes and urinary trichloroacetic acid) in relation to LINE-1 and Alu methylation. They found reduced cord blood Alu and LINE-1 methylation in those with higher blood bromoform levels at their first prenatal visit although this was not statistically significant. This is consistent with prior work on chronic exposure to trihalomethanes through drinking water indicating changes in LINE-1 methylation of granulocytes among healthy subjects and bladder cancer patients and epigenome wide changes in blood DNA methylation after adjusting for blood cell composition among healthy subjects (Salas et al., 2015, 2014). Two studies in healthy volunteers have examined gene expression changes after a short-term exposure to swimming pools, suggesting small and potentially reversible changes in swimmers (Espín-Pérez et al., 2018; Salas et al., 2017). Future studies are needed to confirm or refute these results.

We observed differences in the cord blood composition of newborns from mothers who regularly swam during pregnancy. Specifically, we observed a reduction in the proportions of CD4(+) T lymphocytes and an increase in the proportions of erythroblasts. Earlier toxicological studies showed that exposure to brominated trihalomethanes could induce sister chromatid exchange in human lymphocytes (Landi et al., 1999a). However, in a separate experiment, erythrocytes sequestered and inactivated brominated trihalomethanes, and reduced immunotoxicity in human lymphocytes (Landi et al., 1999b). We can only speculate that our findings reflect physiological compensatory responses to DBP by the fetus. The long-term consequences of the CD4(+) $\mathrm{T}$ lymphocyte changes will be established in future studies.

An important limitation in our study is the lack of the specific swimming pool DPB concentrations and types of DBP compounds experienced by our study participants. Currently, we do not have a biomarker that could reliably capture the swimming pool exposure during pregnancy. The most commonly used biomarker for long term exposure in pregnancy is urinary trichloroacetic acid (Costet et al., 2012; Smith et al., 2013). However, this marker represents ingestion of chlorinated DBPs but not inhaled or absorbed DBPs through the skin as would occur from swimming pools (Dufour et al., 2017). Blood, urine or exhaled breath trihalomethanes only capture short term exposures (inhalation and dermal absorption) and in some cases chronic drinking water exposure (Backer et al., 2008; Rivera-Núñez et al., 2012; P. Yang et al., 2017). They may not, however, reflect the intermittent exposure as might be experienced by swimmers in our study. As mentioned, the organic matter in pools differs from drinking water as it may contain reactive personal care products (World Health Organization, 2006). There are growing concerns regarding potential epigenetic, cytotoxic and genotoxic effects of compounds formed by consumer products such as halobenzoquinones (Wang and Wang, 2013). These compounds, which are not typical found in drinking water, may affect neural stem cells (Fu et al., 2017; Procházka et al., 2015; Wang et al., 2013). In addition, natural humic substances as well as consumer products may generate DBPs with endocrine disrupting activities (Itoh et al., 2009). Such endocrine disruptors could interfere with hormone receptors, hormone synthesis or hormone conversion. Endocrine disruptors are capable of altering neural transmission and the formation of neural networks (Kajta and Wójtowicz, 2013). Animal studies, using artificial mixtures of DBPs detected in drinking water, observed endocrine disrupting effects, but these effects were not found when using trihalomethanes or haloacetic acids alone (Narotsky et al., 2015, 2013). Thus, the driving agents of the DBP mixture toxicity and implicated mechanisms remain an active area of investigation (Plewa et al., 2017).

Swimming is recommended to pregnant women to reduce joint pressure and swelling (Agopian et al., 2013a; "Committee Opinion No. 650", 2015). In small clinical trials, the use of aquatic physical activities during pregnancy improves maternal sleep and reduces of excessive weight gain without affecting the newborn's birth weight (Bacchi et al., 2018; Rodriguez-Blanque et al., 2018). Frequent swimming during pregnancy was inversely related to risk of neural tube defects in the National Birth Defects Prevention Study (adjusted OR: 0.68 96\% CI: 0.47-0.99) (Agopian et al., 2013a). In our study, we adjusted all the models for the total amount and intensity of exercise during pregnancy. Given that duration exercise was not strongly correlated with duration of swimming, and that physical activity was unrelated to head circumference, it is unlikely that our results were due to confounding by exercise. Nonetheless, we cannot fully exclude the possibility of residual confounding.

A further limitation of our study was that we evaluated birth outcomes and did not assess outcomes later in childhood. Birth outcomes (birth weight and head circumference) may impact later neurodevelopmental outcomes based on sibling studies (Matte et al., 2001). In long-term studies, larger head circumference at birth has been inversely related to cognitive decline in both males and females aged 66 to 75 years (Gale et al., 2003). Further, in our study, only 203 out of the 1033 women swam during their pregnancy limiting our statistical power for this analysis. However, we observed an inverse trend in head circumference at birth in our generalized additive models both when we restricted to women who swam $(P=0.01)$ and when we included all women in study $(\mathrm{P}=0.05)$. The long-term clinical implications of the decrease in head circumference we observed are not known, and thus, further follow-up data are needed.

\section{Conclusions}

Our findings suggest swimming in pools during pregnancy may influence children head circumferences at birth and change the cell subpopulations in newborn cord blood. Future studies with longer follow up of the children would help to elucidate the potential health impacts of these observations. Given the overall positive health impacts of exercising during pregnancy, including swimming, the benefits of reducing DBP exposure from pools deserves consideration. 


\section{Acknowledgments}

This work was supported by funds of the National Institutes of Health (NIH) grants P01ES022832, P20GM104416 and R25CA134286 to M.R.K.

\section{Author contributions}

Conceptualization, Lucas A. Salas and Margaret R. Karagas; Data curation, Lucas A. Salas; Formal analysis, Lucas A. Salas; Funding acquisition, Margaret R. Karagas; Investigation, Lucas A. Salas; Methodology, Lucas A. Salas, Emily R. Baker, Mark J. Nieuwenhuijsen, Carmen J. Marsit, Brock C. Christensen and Margaret R. Karagas; Project administration, Margaret R. Karagas; Software, Lucas A. Salas; Supervision, Emily R. Baker, Mark J. Nieuwenhuijsen, Carmen J. Marsit, Brock C. Christensen and Margaret R. Karagas; Visualization, Lucas A. Salas, Brock C. Christensen and Margaret R. Karagas; Writing original draft, Lucas A. Salas, Brock C. Christensen and Margaret R. Karagas; Writing - review \& editing, Lucas A. Salas, Emily R. Baker, Mark J. Nieuwenhuijsen, Carmen J. Marsit, Brock C. Christensen and Margaret R. Karagas.

\section{Competing financial interest}

All authors declare they have no actual or potential competing financial interest.

\section{References}

Agopian, A.J., Lupo, P.J., Canfield, M.A., Mitchell, L.E., National Birth Defects Prevention Study, 2013a. Swimming pool use and birth defect risk. Am. J. Obstet. Gynecol. 209 (219), e1-e9. https://doi.org/10.1016/j.ajog.2013.04.033.

Agopian, A.J., Waller, D.K., Lupo, P.J., Canfield, M. a, Mitchell, L.E., 2013b. A casecontrol study of maternal bathing habits and risk for birth defects in offspring. Environ. Health 12 (88). https://doi.org/10.1186/1476-069X-12-88.

Aryee, M.J., Jaffe, A.E., Corrada-Bravo, H., Ladd-Acosta, C., Feinberg, A.P., Hansen, K.D., Irizarry, R.A., 2014. Minfi: a flexible and comprehensive bioconductor package for the analysis of infinium DNA methylation microarrays. Bioinformatics 30 , 1363-1369. https://doi.org/10.1093/bioinformatics/btu049.

Bacchi, M., Mottola, M.F., Perales, M., Refoyo, I., Barakat, R., 2018. Aquatic activities during pregnancy prevent excessive maternal weight gain and preserve birth weight: a randomized clinical trial. Am. J. Health Promot. 32, 729-735. https://doi.org/10. 1177/0890117117697520.

Backer, L.C., Lan, Q., Blount, B.C., Nuckols, J.R., Branch, R., Lyu, C.W., Kieszak, S.M., Brinkman, M.C., Gordon, S.M., Flanders, W.D., Romkes, M., Cantor, K.P., 2008. Exogenous and endogenous determinants of blood trihalomethane levels after showering. Environ. Health Perspect. 116, 57-63. https://doi.org/10.1289/ehp. 10049.

Bakulski, K.M., Feinberg, J.I., Andrews, S.V., Yang, J., Brown, S., L. McKenney, S., Witter, F., Walston, J., Feinberg, A.P., Fallin, M.D., 2016. DNA methylation of cord blood cell types: applications for mixed cell birth studies. Epigenetics 11, 354-362. https://doi. org /10.1080/15592294.2016.1161875.

Benjamini, Y., Hochberg, Y., 1995. Controlling the false discovery rate: a practical and powerful approach to multiple testing. J. R. Stat. Soc. Ser. B 57, 289-300.

Cardenas, A., Koestler, D.C., Houseman, E.A., Jackson, B.P., Kile, M.L., Karagas, M.R., Marsit, C.J., 2015. Differential DNA methylation in umbilical cord blood of infants exposed to mercury and arsenic in utero. Epigenetics 10, 508-515. https://doi.org/ 10.1080/15592294.2015.1046026.

Chowdhury, S., Alhooshani, K., Karanfil, T., 2014. Disinfection byproducts in swimming pool: occurrences, implications and future needs. Water Res. 53, 68-109. https://doi. org/10.1016/j.watres.2014.01.017.

Committee Opinion No. 650, 2015. Obstet. Gynecologie 126, e135-e142. https://doi.org/ 10.1097/AOG.0000000000001214.

Costet, N., Villanueva, C.M., Jaakkola, J.J.K., Kogevinas, M., Cantor, K.P., King, W.D., Lynch, C.F., Nieuwenhuijsen, M.J., Cordier, S., 2011. Water disinfection by-products and bladder cancer: is there a European specificity? A pooled and meta-analysis of European case-control studies. Occup. Environ. Med. 68, 379-385. https://doi.org/ 10.1136/oem.2010.062703.

Costet, N., Garlantézec, R., Monfort, C., Rouget, F., Gagnière, B., Chevrier, C., Cordier, S., 2012. Environmental and urinary markers of prenatal exposure to drinking water disinfection by-products, fetal growth, and duration of gestation in the PELAGIE birth cohort (Brittany, France, 2002-2006). Am. J. Epidemiol. 175, 263-275. https://doi. org/10.1093/aje/kwr419.

De Filippis, P., Mozzetti, C., Amicosante, M., D'Alò, G.L., Messina, A., Varrenti, D., Giammattei, R., Di Giorgio, F., Corradi, S., D'Auria, A., Fraietta, R., Gabrieli, R., 2017. Occurrence of Legionella in showers at recreational facilities. J. Water Health 15, 402-409. https://doi.org/10.2166/wh.2017.296. de Goede, O.M., Lavoie, P.M., Robinson, W.P., 2016. Characterizing the hypomethylated DNA methylation profile of nucleated red blood cells from cord blood. Epigenomics 8, 1481-1494. https://doi.org/10.2217/epi-2016-0069.

Dufour, A.P., Behymer, T.D., Cantú, R., Magnuson, M., Wymer, L.J., 2017. Ingestion of swimming pool water by recreational swimmers. J. Water Health 15, 429-437. https://doi.org/10.2166/wh.2017.255.

Ekowati, Y., van Diepeningen, A.D., Ferrero, G., Kennedy, M.D., de Roda Husman, A.M., Schets, F.M., 2017. Clinically relevant fungi in water and on surfaces in an indoor swimming pool facility. Int. J. Hyg. Environ. Health 220, 1152-1160. https://doi. org/10.1016/j.ijheh.2017.07.002.

Espín-Pérez, A., Font-Ribera, L., van Veldhoven, K., Krauskopf, J., Portengen, L., Chadeau-Hyam, M., Vermeulen, R., Grimalt, J.O., Villanueva, C.M., Vineis, P., Kogevinas, M., Kleinjans, J.C., de Kok, T.M., 2018. Blood transcriptional and microRNA responses to short-term exposure to disinfection by-products in a swimming pool. Environ. Int. 110, 42-50. https://doi.org/10.1016/j.envint.2017.10.003.

Fenton, T.R., Kim, J.H., 2013. A systematic review and meta-analysis to revise the Fenton growth chart for preterm infants. BMC Pediatr. 13 (59). https://doi.org/10.1186/ 1471-2431-13-59.

Fortin, J., Labbe, A., Lemire, M., Zanke, B.W., Hudson, T.J., Fertig, E.J., Greenwood, C., Hansen, K.D., 2014. Functional normalization of 450k methylation array data improves replication in large cancer studies. Genome Biol. 15, 503. https://doi.org/10. 1101/002956.

Fortin, J.-P., Triche, T.J., Hansen, K.D., 2017. Preprocessing, normalization and integration of the Illumina HumanMethylationEPIC array with minfi. Bioinformatics 33, 558-560. https://doi.org/10.1093/bioinformatics/btw691.

Fu, K.Z., Li, J., Vemula, S., Moe, B., Li, X., 2017. Effects of halobenzoquinone and haloacetic acid water disinfection byproducts on human neural stem cells. J. Environ. Sci. 1-11. https://doi.org/10.1016/j.jes.2017.02.006.

Gale, C.R., Walton, S., Martyn, C.N., 2003. Foetal and postnatal head growth and risk of cognitive decline in old age. Brain 126, 2273-2278. https://doi.org/10.1093/brain/ awg225.

Gervin, K., Page, C.M., Aass, H.C.D., Jansen, M.A., Fjeldstad, H.E., Andreassen, B.K., Duijts, L., van Meurs, J.B., van Zelm, M.C., Jaddoe, V.W., Nordeng, H., Knudsen, G.P., Magnus, P., Nystad, W., Staff, A.C., Felix, J.F., Lyle, R., 2016. Cell type specific DNA methylation in cord blood: a 450K-reference data set and cell count-based validation of estimated cell type composition. Epigenetics 11, 690-698. https://doi.org/10. $1080 / 15592294.2016 .1214782$

Gilbert-Diamond, D., Cottingham, K.L., Gruber, J.F., Punshon, T., Sayarath, V., Gandolfi, A.J., Baker, E.R., Jackson, B.P., Folt, C.L., Karagas, M.R., 2011. Rice consumption contributes to arsenic exposure in US women. Proc. Natl. Acad. Sci. U. S. A. 108, 20656-20660. https://doi.org/10.1073/pnas.1109127108.

Grellier, J., Bennett, J., Patelarou, E., Smith, R.B., Toledano, M.B., Rushton, L., Briggs, D.J., Nieuwenhuijsen, M.J., 2010. Exposure to disinfection by-products, fetal growth, and prematurity: a systematic review and meta-analysis. Epidemiology 21, 300-313. https://doi.org/10.1097/EDE.0b013e3181d61ffd.

Houseman, E.A., Accomando, W.P., Koestler, D.C., Christensen, B.C., Marsit, C.J., Nelson, H.H., Wiencke, J.K., Kelsey, K.T., 2012. DNA methylation arrays as surrogate measures of cell mixture distribution. BMC Bioinf. 13, 86. https://doi.org/10.1186/1471. 2105-13-86.

Hutcheon, J.A., Platt, R.W., Abrams, B., Himes, K.P., Simhan, H.N., Bodnar, L.M., 2013. A weight-gain-for-gestational-age $\mathrm{z}$ score chart for the assessment of maternal weight gain in pregnancy. Am. J. Clin. Nutr. 97, 1062-1067. https://doi.org/10.3945/ajcn. 112.051706

Itoh, S., Yoshimura, Y., Okada, T., 2009. Components of estrogenic effect in chlorinated drinking water. Adv, Asian Environ. Eng. 8, 31-38.

Johnson, W.E., Li, C., Rabinovic, A., 2007. Adjusting batch effects in microarray expression data using empirical Bayes methods. Biostatistics 8, 118-127. https://doi. org/10.1093/biostatistics/kxj037.

Juhl, M., Kogevinas, M., Andersen, P.K., Andersen, A.-M.N., Olsen, J., 2010. Is swimming during pregnancy a safe exercise? Epidemiology 21, 253-258. https://doi.org/10. 1097/EDE.0b013e3181cb6267.

Kajta, M., Wójtowicz, A.K., 2013. Impact of endocrine-disrupting chemicals on neural development and the onset of neurological disorders. Pharmacol. Rep. 65, 1632-1639. https://doi.org/10.1016/S1734-1140(13)71524-X.

Koestler, D.C., Avissar-Whiting, M., Houseman, E.A., Karagas, M.R., Marsit, C.J., 2013. Differential DNA methylation in umbilical cord blood of infants exposed to low levels of arsenic in utero. Environ. Health Perspect. 121, 971-977. https://doi.org/10. 1289/ehp.1205925.

Koestler, D.C., Jones, M.J., Usset, J., Christensen, B.C., Butler, R.A., Kobor, M.S., Wiencke, J.K., Kelsey, K.T., 2016. Improving cell mixture deconvolution by identifying optimal DNA methylation libraries (IDOL). BMC Bioinf. 17 (120). https://doi.org/10.1186/ s12859-016-0943-7.

Kogevinas, M., Villanueva, C.M., Font-Ribera, L., Liviac, D., Bustamante, M., Espinoza, F., Nieuwenhuijsen, M.J., Espinosa, A., Fernandez, P., DeMarini, D.M., Grimalt, J.O., Grummt, T., Marcos, R., 2010. Genotoxic effects in swimmers exposed to disinfection by-products in indoor swimming pools. Environ. Health Perspect. 118, 1531-1537. https://doi.org/10.1289/ehp.1001959.

Landi, S., Hanley, N.M., Kligerman, A.D., DeMarini, D.M., 1999a. Induction of sister chromatid exchanges in human peripheral blood lymphocytes by bromoform: investigation of the role of GSTT1-1 polymorphism. Mutat. Res. 429, 261-267. https:// doi.org/10.1016/S0027-5107(99)00107-4.

Landi, S., Hanley, N.M., Warren, S.H., Pegram, R. a, DeMarini, D.M., 1999b. Induction of genetic damage in human lymphocytes and mutations in Salmonella by trihalomethanes: role of red blood cells and GSTT1-1 polymorphism. Mutagenesis 14, 479-482. https://doi.org/10.1093/mutage/14.5.479.

Leek, J.T., Johnson, W.E., Parker, H.S., Jaffe, A.E., Storey, J.D., 2012. The sva package for 
removing batch effects and other unwanted variation in high-throughput experiments. Bioinformatics 28, 882-883. https://doi.org/10.1093/bioinformatics/bts034.

Lourencetti, C., Grimalt, J.O., Marco, E., Fernandez, P., Font-Ribera, L., Villanueva, C.M., Kogevinas, M., 2012. Trihalomethanes in chlorine and bromine disinfected swimming pools: air-water distributions and human exposure. Environ. Int. 45, 59-67. https://doi.org/10.1016/j.envint.2012.03.009.

Manasfi, T., Coulomb, B., Boudenne, J.-L., 2017. Occurrence, origin, and toxicity of disinfection byproducts in chlorinated swimming pools: an overview. Int. J. Hyg. Environ. Health 220, 591-603. https://doi.org/10.1016/j.ijheh.2017.01.005.

Matte, T.D., Bresnahan, M., Begg, M.D., Susser, E., 2001. Influence of variation in birth weight within normal range and within sibships on IQ at age 7 years: cohort study. BMJ 323, 310-314. https://doi.org/10.1136/bmj.323.7308.310.

Narotsky, M.G., Klinefelter, G.R., Goldman, J.M., Best, D.S., McDonald, A., Strader, L.F., Suarez, J.D., Murr, A.S., Thillainadarajah, I., Hunter, E.S., Richardson, S.D., Speth, T.F., Miltner, R.J., Pressman, J.G., Teuschler, L.K., Rice, G.E., Moser, V.C., Luebke, R.W., Simmons, J.E., 2013. Comprehensive assessment of a chlorinated drinking water concentrate in a rat multigenerational reproductive toxicity study. Environ. Sci. Technol. 47, 10653-10659. https://doi.org/10.1021/es402646c.

Narotsky, M.G., Klinefelter, G.R., Goldman, J.M., DeAngelo, A.B., Best, D.S., McDonald, A., Strader, L.F., Murr, A.S., Suarez, J.D., George, M.H., Hunter, E.S., Simmons, J.E. 2015. Reproductive toxicity of a mixture of regulated drinking-water disinfection byproducts in a multigenerational rat bioassay. Environ. Health Perspect. 564, 564-570. https://doi.org/10.1289/ehp.1408579.

Nieuwenhuijsen, M.J., Northstone, K., Golding, J., the ALSPAC Study Team, 2002. Swimming and birth weight. Epidemiology 13, 725-728. https://doi.org/10.1097/ 01.EDE.0000030722.16351.91.

Nieuwenhuijsen, M.J., Martinez, D., Grellier, J., Bennett, J., Best, N., Iszatt, N., Vrijheid, M., Toledano, M.B., 2009. Chlorination disinfection by-products in drinking water and congenital anomalies: review and meta-analyses. Environ. Health Perspect. 117, 1486-1493. https://doi.org/10.1289/ehp.0900677.

Nieuwenhuijsen, M.J., Dadvand, P., Grellier, J., Martinez, D., Vrijheid, M., 2013 Environmental risk factors of pregnancy outcomes: a summary of recent meta-analyses of epidemiological studies. Environ. Health 12 (6). https://doi.org/10.1186/ 1476-069X-12-6.

Patelarou, E., Kargaki, S., Stephanou, E.G., Nieuwenhuijsen, M., Sourtzi, P., Gracia, E., Chatzi, L., Koutis, A., Kogevinas, M., 2011. Exposure to brominated trihalomethanes in drinking water and reproductive outcomes. Occup. Environ. Med. 68, 438-445. https://doi.org/10.1136/oem.2010.056150.

Philibert, R.A., Beach, S.R.H., Brody, G.H., 2014. The DNA methylation signature of smoking: an archetype for the identification of biomarkers for behavioral illness. Neb. Symp. Motiv. 61, 109-127. https://doi.org/10.1007/978-1-4939-0653-6 6.

Plewa, M.J., Wagner, E.D., Richardson, S.D., 2017. TIC-Tox: a preliminary discussion on identifying the forcing agents of DBP-mediated toxicity of disinfected water. J. Environ. Sci. 58, 208-216. https://doi.org/10.1016/j.jes.2017.04.014.

Procházka, E., Escher, B.I., Plewa, M.J., Leusch, F.D.L., 2015. In vitro cytotoxicity and adaptive stress responses to selected haloacetic acid and halobenzoquinone water disinfection byproducts. Chem. Res. Toxicol. 28, 2059-2068. https://doi.org/10. 1021/acs.chemrestox.5b00283.

R Core Team, 2017. R: A Language and Environment for Statistical Computing.

Reese, S.E., Zhao, S., Wu, M.C., Joubert, B.R., Parr, C.L., Håberg, S.E., Ueland, P.M., Nilsen, R.M., Midttun, Ø., Vollset, S.E., Peddada, S.D., Nystad, W., London, S.J., 2017. DNA methylation score as a biomarker in newborns for sustained maternal smoking during pregnancy. Environ. Health Perspect. 125, 760-766. https://doi.org/ 10.1289/EHP333.

Reinius, L.E., Acevedo, N., Joerink, M., Pershagen, G., Dahlén, S.E., Greco, D., Söderhäll, C., Scheynius, A., Kere, J., 2012. Differential DNA methylation in purified human blood cells: implications for cell lineage and studies on disease susceptibility. PLoS One 7. https://doi.org/10.1371/journal.pone.0041361.

Richardson, S.D., DeMarini, D.M., Kogevinas, M., Fernandez, P., Marco, E., Lourencetti, C., Ballesté, C., Heederik, D., Meliefste, K., McKague, A.B., Marcos, R., Font-Ribera L., Grimalt, J.O., Villanueva, C.M., 2010. What's in the pool? A comprehensive identification of disinfection by-products and assessment of mutagenicity of chlorinated and brominated swimming pool water. Environ. Health Perspect. 118, 1523-1530. https://doi.org/10.1289/ehp.1001965.

Ritchie, M.E., Phipson, B., Wu, D., Hu, Y., Law, C.W., Shi, W., Smyth, G.K., 2015. limma powers differential expression analyses for RNA-sequencing and microarray studies. Nucleic Acids Res. 43, e47. https://doi.org/10.1093/nar/gkv007.

Rivera-Núñez, Z., Wright, J.M., Blount, B.C., Silva, L.K., Jones, E., Chan, R.L., Pegram, R. a, Singer, P.C., Savitz, D.A., 2012. Comparison of trihalomethanes in tap water and blood: a case study in the United States. Environ. Health Perspect. 120, 661-667. https://doi.org/10.1289/ehp.1104347.

Rodriguez-Blanque, R., Sánchez-García, J.C., Sánchez-López, A.M., Mur-Villar, N., Aguilar-Cordero, M.J., 2018. The influence of physical activity in water on sleep quality in pregnant women: a randomised trial. Women Birth 31, e51-e58. https:// doi.org/10.1016/j.wombi.2017.06.018.

Salas, L.A., Villanueva, C.M., Tajuddin, S.M., Amaral, A.F.S., Fernandez, A.F., Moore, L.E. Carrato, A., Tardón, A., Serra, C., García-Closas, R., Basagaña, X., Rothman, N., Silverman, D.T., Cantor, K.P., Kogevinas, M., Real, F.X., Fraga, M.F., Malats, N., 2014 LINE-1 methylation in granulocyte DNA and trihalomethane exposure is associated with bladder cancer risk. Epigenetics 9, 1532-1539. https://doi.org/10.4161/ 15592294.2014.983377.

Salas, L.A., Bustamante, M., Gonzalez, J.R., Gracia-Lavedan, E., Moreno, V., Kogevinas, M., Villanueva, C.M., 2015. DNA methylation levels and long-term trihalomethane exposure in drinking water: an epigenome-wide association study. Epigenetics 10, 650-661. https://doi.org/10.1080/15592294.2015.1057672.

Salas, L.A., Font-Ribera, L., Bustamante, M., Sumoy, L., Grimalt, J.O., Bonnin, S., Aguilar, M., Mattlin, H., Hummel, M., Ferrer, A., Kogevinas, M., Villanueva, C.M., 2017. Gene expression changes in blood RNA after swimming in a chlorinated pool. J. Environ. Sci. (China) 58, 250-261. https://doi.org/10.1016/j.jes.2017.05.011.

Salas, L.A., Koestler, D.C., Butler, R.A., Hansen, H.M., Wiencke, J.K., Kelsey, K.T. Christensen, B.C., 2018a. An optimized library for reference-based deconvolution of whole-blood biospecimens assayed using the Illumina HumanMethylationEPIC BeadArray. Genome Biol. 19 (64). https://doi.org/10.1186/s13059-018-1448-7.

Salas, L.A., Koestler, D.C., Butler, R.A., Hansen, H.M., Wiencke, J.K., Kelsey, K.T., Christensen, B.C., 2018b. FlowSorted.Blood.EPIC [WWW document]. Bioconductor. https://doi.org/10.18129/B9.bioc.FlowSorted.Blood.EPIC.

Smith, R.B., Nieuwenhuijsen, M.J., Wright, J., Raynor, P., Cocker, J., Jones, K., Kostopoulou-Karadanelli, M., Toledano, M.B., 2013. Validation of trichloroacetic acid exposure via drinking water during pregnancy using a urinary TCAA biomarker. Environ. Res. 126, 145-151. https://doi.org/10.1016/j.envres.2013.05.004.

Stayner, L.T., Pedersen, M., Patelarou, E., Decordier, I., Vande Loock, K., Chatzi, L., Espinosa, A., Fthenou, E., Nieuwenhuijsen, M.J., Gracia-Lavedan, E., Stephanou, E.G., Kirsch-Volders, M., Kogevinas, M., 2014. Exposure to brominated trihalomethanes in water during pregnancy and micronuclei frequency in maternal and cord blood lymphocytes. Environ. Health Perspect. 122, 100-106. https://doi.org/10.1289/ehp. 1206434.

Van-Buuren, S., Groothuis-Oudshoorn, K., 2011. mice: multivariate imputation by chained equations in R. J. Stat. Softw. 45. https://doi.org/10.18637/jss.v045.i03.

Villanueva, C.M., Gagniere, B., Monfort, C., Nieuwenhuijsen, M.J., Cordier, S., 2007. Sources of variability in levels and exposure to trihalomethanes. Environ. Res. 103, 211-220. https://doi.org/10.1016/j.envres.2006.11.001.

Villanueva, C.M., Gracia-Lavedán, E., Ibarluzea, J., Santa Marina, L., Ballester, F., Llop, S., Tardón, A., Fernández, M.F., Freire, C., Goñi, F., Basagaña, X., Kogevinas, M., Grimalt, J.O., Sunyer, J., 2011. Exposure to trihalomethanes through different water uses and birth weight, small for gestational age, and preterm delivery in Spain. Environ. Health Perspect. 119, 1824-1830. https://doi.org/10.1289/ehp.1002425.

Villanueva, C.M., Cordier, S., Font-Ribera, L., Salas, L.A., Levallois, P., 2015. Overview of disinfection by-products and associated health effects. Curr. Environ. Health Rep. 2 107-115. https://doi.org/10.1007/s40572-014-0032-x.

Wang, X., Wang, H., 2013. Epigenotoxicity of environmental pollutants evaluated by a combination of DNA methylation inhibition and capillary electrophoresis-laser-induced fluorescence immunoassay. Anal. Bioanal. Chem. 405, 2435-2442. https://doi. org/10.1007/s00216-013-6717-4.

Wang, W., Qian, Y., Boyd, J.M., Wu, M., Hrudey, S.E., Li, X.-F., 2013. Halobenzoquinones in swimming pool waters and their formation from personal care products. Environ. Sci. Technol. 47, 3275-3282. https://doi.org/10.1021/es304938x.

World Health Organization, 2006. Guidelines for Safe Recreational Water Environments. vol. 2 WHO Press, Geneva, Switzerland.

Wright, J.M., Hoffman, C.S., Nieuwenhuijsen, M.J., Savitz, D.a., 2011. The effect of swimming during pregnancy on fetal growth. Water Qual Expo Health 3, 217-223. https://doi.org/10.1007/s12403-011-0057-4.

Xu, Z., Niu, L., Li, L., Taylor, J.A., 2016. ENmix: a novel background correction method for Illumina HumanMethylation450 BeadChip. Nucleic Acids Res. 44, e20. https:// doi.org/10.1093/nar/gkv907.

Yang, Y., Ok, Y.S., Kim, K.H., Kwon, E.E., Tsang, Y.F., 2017a. Occurrences and removal of pharmaceuticals and personal care products (PPCPs) in drinking water and water/ sewage treatment plants: a review. Sci. Total Environ. 596-597, 303-320. https:// doi.org/10.1016/j.scitotenv.2017.04.102.

Yang, P., Zhou, B., Cao, W.-C., Wang, Y.-X., Huang, Z., Li, J., Lu, W.-Q., Zeng, Q., 2017b. Prenatal exposure to drinking water disinfection by-products and DNA methylation in cord blood. Sci. Total Environ. 586, 313-318. https://doi.org/10.1016/j.scitotenv. 2017.01.224.

Zhou, W., Laird, P.W., Shen, H., 2017. Comprehensive characterization, annotation and innovative use of Infinium DNA methylation BeadChip probes. Nucleic Acids Res. 45, e22. https://doi.org/10.1093/nar/gkw967. 